\title{
Walking the Creek: Reconnecting place through light projection
}

\section{Tim Edensor and Julie Andrews}

\section{Tim Edensor}

Level 1

221 Bouverie Street

University of Melbourne

Carlton, Melbourne

Victoria

Austyralia

3053

t.edensor@mmu.ac.uk

\section{$\underline{\text { Julie Andrews }}$}

Visual Artist

PO Box 1001

Maiden Gully

Bendigo

Victoria

Australia

$3551-$

JulieAndrewsArt@gmail.com

\section{Walking the Creek: Reconnecting place through light projection}

This is the author manuscript accepted for publication and has undergone full peer review but has not been through the copyediting, typesetting, pagination and proofreading process, which may lead to differences between this version and the Version of Record. Please cite this article as doi: $10.1111 / 1745-5871.12340$

This article is protected by copyright. All rights reserved. 


\begin{abstract}
In this paper, we explore how a light projection sought to convey a range of qualities: conviviality, a sense of place, playfulness, defamiliarization, and the affective and sensory capacities that were experienced through walking in the distinctive, liminal realm of Bendigo Creek. The projection aspired to solicit a sensory and affective empathy that chimed with the experiences of an earlier event in which dozens of pedestrians were filmed walking in the Creek. The projection contributed to a local campaign to reappraise the much-maligned Creek as a local public amenity. We discuss the productive potential of solitary and collective walking, and subsequently, the attributes of the projection in its static and mobile manifestation. In so doing, we suggest that publicly engaged, inclusive creative practice can offer potent place-making possibilities.
\end{abstract}

Key words: walking; light projection, place; liminality; ludic; remixing

\title{
Introduction
}

This paper is concerned with a light projection, Beyond the Horizon: The Lure of the Liminal Journey, staged at Bendigo's Enlighten festival. With its creation, we sought to convey a range of qualities: conviviality, a sense of place, playfulness, defamiliarization, and the affective and sensory capacities experienced by walking in the distinctive, liminal realm of Bendigo Creek. After introducing the geographical context of the paper, we consider how walking has been considered as a critical practice, focusing upon the possibilities afforded by both solitary and collective walking, with both practices integral to the project. We show how solitary walking attuned us to the distinctive qualities of the Creek. We also show how a subsequent collective walking event, which was filmed, provided the basis for the subsequent projection, and helped us advance some of the ideas about place-making and reterritorialization that we sought to explore. Following this introduction, we discuss the projection itself, focusing upon: its liminal qualities; its presentation of conviviality and solicitation of sensory and affective empathy; the ways in which it reconfigured nocturnal 
space; and its function in offering a reappreciation of the much-maligned Creek as a valuable public amenity. Finally, we discuss the potential that mobile projection has to prompt people to further critically engage with and defamiliarize the nocturnal urban environment. Both forms of projection challenged and augmented the usual nightscape, defamiliarizing usual sensory and affective experience of space, challenging normative uses and feelings. In addition to this work to make the familiar strange with light, we contend that collaborative and inclusive creative practices such as this can offer progressive approaches to place-making that communicate alternative identities-political ideas and cultural values that diverges from neo-liberal strategies (Courage \& McKeown, 2018).

Bendigo Creek was supposedly named in honour of a local pugilistic shepherd who had been nicknamed after the celebrated English prize-fighter, William 'Bendigo' Thompson. The creek runs south-west to north-east through the centre of the city of Bendigo, in Victoria, Australia. Formerly it was a small sheep station and now has a current population of nearly 100,000. An early map shows that the Creek had been stewarded by local Aborigines, with six or seven interlinked ponds that supplied drinkable clear water and fish; treeless environs were managed by the regular burning of the surrounding forest. This verdant, grassy setting, inhabited by platypus and kingfishers, was irretrievably altered with the advent of sheep and cattle farming; the banks of the creek were trampled and creek-side plants were eaten. This was devastating to the indigenous population, and a precursor to the much more substantial impacts on the environment following the discovery of alluvial gold in the area in 1851, as a multicultural horde of diggers descended on the town to seek their fortune (see Waterton, 2018).

The wealth produced through gold mining led to the establishment of a thriving civic culture, marked by the exuberant nineteenth century buildings that line Bendigo's central streets. Designed in diverse, elaborate styles, and accompanied by luxuriant squares and parks, these buildings convey monumentality and grandeur. Yet despite these extravagant surroundings, the Creek became marginalised even though it runs through the centre of the city.

Abundant water was crucial to nineteenth century gold mining, as pans and sluice boxes were used to separate gold from soil, clay and gravel. Puddling mills, ring-shaped troughs in which 
the alluvial deposits were mixed with water so that the heavier gold would sink to the bottom, were later deployed along with hydraulic sluicing-powerful jets of water directed at the sides of gullies. This daily deployment of millions of gallons cascaded sediment down creeks, changing river courses and causing erosion. This influx hugely affected Bendigo's modest creek, which periodically overflowed with a thick sludge that accumulated from its numerous tributaries. The deluge engulfed parts of the town and deposited an infertile, often toxic layer of sludge that buried the soil across 735 square kilometers of farming land as far as 100 miles away (Lawrence et al., 2013).

The sludge problem reverberated throughout the nineteenth century, and local authorities and business owners sought to alleviate its malign effects. A Royal Commission-the 'sludge' commission - was established in 1859 to deal with the dilemma. In the 1860 s, a ten-mile timber box drain was constructed along the Creek to divert the sludge away from businesses and homes. Crucially, from 1910 to 1915, the Creek was deepened and straightened for over three miles and lined with bluestone setts. This striking stone design constitutes a unique form of canalisation and is now heritage listed. At either end of this bluestone segment, short sections of concrete were later laid down. Accordingly, since those times, the Creek has been conceived and treated as a large drain, even though for most of the year only a small channel cut into its base contains flowing water; the remainder of the waterway provides wide, gently-sloping surfaces.

However, recent reassessments have highlighted the Creek's potential as a valuable local amenity, championing possibilities for walking, cycling, encountering historical features, and forging ecological improvements. This re-evaluation has involved local students from La Trobe University in exploring how alternative practices of planning, archaeology and nature conservation might be undertaken, including investigations into whether earlier indigenous agricultural methods might be redeployed (Kernebone, 2018). A Land Care group has been established to replant some areas of surrounding land and erect nesting boxes. Consequent improvements in water quality and riverside vegetation have encouraged certain species, notably Growling Grass Frogs, to return to the Creek. 
Despite these reappraisals and improvements, in most places along its course, Bendigo Creek remains inaccessible to walkers and cyclists. Associations with the abject substances that have flowed through it linger, and it continues to be imagined as a dangerous, isolated space. It is in this context that the walking event and subsequent light projection was devised to contribute to the ongoing project to revalue the Creek.

\section{Walking the Creek}

The light projection, Beyond the Horizon: The Lure of the Liminal Journey, focuses on a short walk in the Creek that took place on a cool autumnal afternoon. A call for participation —advertised as a "flash mob style walk" —was issued in early July in local radio, press and social media, with the explicit message that participants would be filmed for an art work to be created as part of the Enlighten Projection Festival in late August. Would-be-attendees were advised that the walk would occur between 1:45 and 3:30 p.m. and would conclude with the provision of hot food.

The project was inspired by the increasing popularity of walking as a subject for scholarly and artistic exploration. Walking has become a focus of discussion across many academic disciplines (Pink et al., 2010) and creative practitioners have deployed walking as a mode of inquiry, frequently dwelling on 'its potentialities for experiencing, researching, weaving, reenchanting, or subverting spaces' (Pinder, 2011, p.675). These explorations amply demonstrate that walking is multidimensional in its social significance and modes of practice. Walking can solicit intensely felt experiences or be part of unreflexive mundane routines, be carried out in states of focused concentration or distraction. In identifying the plethora of practices and inspirations, Rybra $\square$ ten et al. (2017) discuss how walking is undertaken to improve health, for leisure, as a routine passage to work, or to forge companionship. Moreover, different styles (Kay \& Moxham, 1996) vary from shuffling, striding, promenading, rambling, loitering, dawdling, sauntering or scrutinising.

A key notion asserts that walking is motivated as a means to subvert the baleful effects of capitalism and bureaucracy. In striding away from passive consumption or in defiance of 
highly regulated spaces, Rebecca Solnit (2000, p.11) considers that walking 'is one way of maintaining a bulwark against (the) erosion of the mind, the body, the landscape and the city, and every walker is on guard to protect the ineffable'. In also advocating walking as a political tool, Katrina Brown (2012, p.803) contends that 'the struggle for public space does not just take place through the pages of legislation or Codes but in the spaces of bodily encounter'. Such conceptions inspired the practices of the situationists and those they have subsequently influenced (Bassett, 2004). By organising dérives or psychogeographic adventures, often with absurdist, surreal, or random objectives, they have sought to subvert dominant understandings about the use, meaning and experience of space, including through the use of the technique of détournement, referred to later. In contrast to our walks in the Creek, these playful and often arcane projects are typically purposive, focusing on particular objectives and focal points; they thus diverge from attempts to reclaim public space that more overtly communicate their intentions and ideas.

In conceiving walking as a critical practice, Michel de Certeau (1984) distinguishes between the strategies of the powerful that seek to classify and territorialise space and the tactics of ordinary pedestrians who fleetingly appropriate these realms. In conceiving the pedestrian as a figure who continuously reads and writes spaces idiosyncratically, he considers that powerful disciplinary systems of prescription and surveillance are bypassed, along with norms of mobility: where to go and avoid, how to move, at what speed and with whom. Here, we consider solitary walking as a critical practice that fosters acquaintance with previously unfamiliar space. In order to inform our plan to organise the proposed collective walk through the creek, we undertook several solitary walks along its length to become attuned to this linear space and to select where the filming might take place.

Walking along the Creek alone underlined how place is always emergent, endlessly recomposed by shifting events, changing materialities and active humans and non-humans. As walking humans, we accompany the birds that fly above, the water that courses through, the moss that grows in the cracks of the setts, the plants that sprout through fissures, the insects that scurry across surfaces, and the lithic and wooden materialities that slowly decay and mutate. Our feet change the soundscape and contribute to the shifting materiality of the 
surfaces on which we walk, even if minutely. Accordingly, we are agents in the continuous emergence of the city and are ourselves in a state of becoming with the landscape as we move with it. As Tim Ingold (2007, p. S32) emphasises, humans 'make their way through a worldin-formation rather than across its pre-formed surface'. As we are cajoled into adapting our movements and sensing its affordances (Edensor, 2008), we territorialise and 'forge a corporeal alignment with place' (Waitt et al., 2009, p. 44).

In the Creek, as elsewhere, as Jennifer Gabrys (2012, p.2936) claims, through walking we may 'form relationships to environments and more-than-humans ... a practical method that connects up places and experiences' and allows sites to 'emerge through the relations that walking sets in motion'. Walking is simultaneously purposive but allows for digression and improvisation, is apt to stimulate sudden shifts of mood, distractions, previously unnoticed elements, reverie and forward-planning, and social engagement. Affective and sensory experience changes in response to the 'shifting mood, tenor, colour or intensity of place and situation' (Wylie, 2005, p.236), and are part of the flow of walking, of the connections made with and away from the landscape (Lund, 2012). In offering an immersed and embodied sense of place, the Creek affords a range of sensory and social experiences and directs walking in particular ways.

Walking the Creek alternately reveals long, broad vistas and locations at which bodies must adapt to bends and underpasses. Most obviously, the Creek is composed out of discrete sections: the portion that passes through the centre of Bendigo demarcated by bluestone, the smoother passages either side of this forged in concrete, and the grassy, tree-lined banks, reed beds and weedy underwater vegetation of the less regulated, pastoral areas at either end (Figure 1).
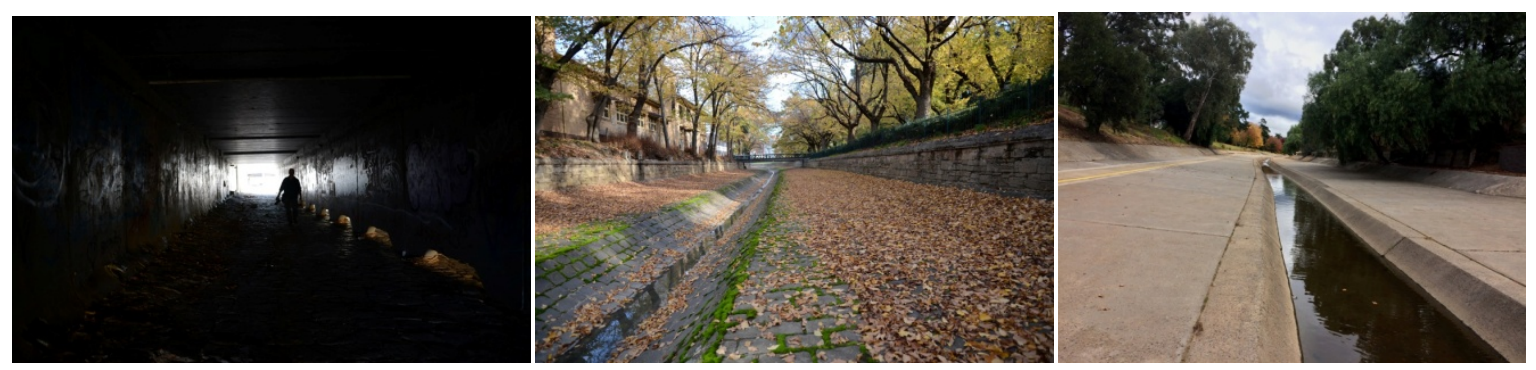


\section{Figure 1: Sections of the Creek}

These distinctive materialities shape the shifting qualities of walking, as feet negotiate angled and irregular bluestone setts, saunter over smooth and flat concrete, tramp over the earthy path that runs alongside the more arboreal sections and stoop to move through low tunnels. The lack of access to the Creek along most urban stretches mean that entry may only be gained through a careful climb over walls; this also limits possibilities for taking improvisatory diversions beyond its linear boundaries.

Plentiful diversions are afforded by the shifting array of stone and concrete that line the Creek, obsolete and blocked drains, forms of decay and techniques of repair, the looming form of the Chinese temple, the dazzling foliage of the trees in the botanical gardens, the echoes made by footsteps under bridges, the back gardens of adjacent houses, the harsh cries of the crows that congregate on nearby fixtures, the discarded items and debris left high and dry by recent flood surges, and the thick moss that clads areas of the bluestone (Figure 2).
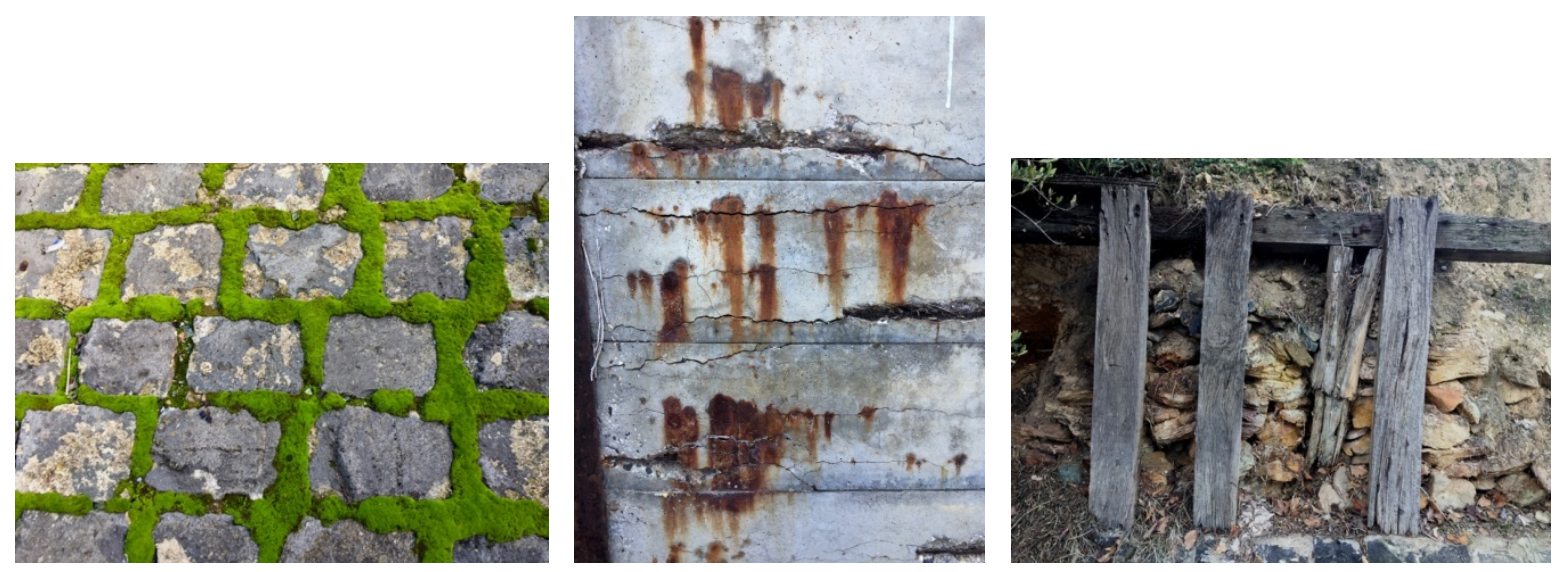

\section{Figure 2: textures of the Creek}

Apart from these non-human elements, few impediments to walking exist. There are no passing or oncoming vehicles to avoid, and so these diverse material configurations and constantly changing surroundings make the Creek a pleasurable place in which to walk, with birdsong, the flow of water and the rustle of wind largely predominating over the noise of traffic. This relative quiescence might be apprehended as unnerving or peaceful and is 
especially striking at the Creek passes through the centre of town. Rarely traversed by pedestrians over preceding decades, walkers have left few physical traces of their presence.

Walking attunes us to the distinct qualities of the routes and landscapes through which we pass, and yet walking, especially along a marginal route such as the Creek, can also disrupt the habitual encounter with place, defamiliarizing the experience of the local. Apprehending the city from a wholly different perspective, moving through urban space that is suffused with unfamiliar sensations and affects, can render the familiar environment strange, untether formerly unreflexive assumptions about the quality of place. In the Creek, participants may thus reconsider the qualities of what they had previously regarded as an abject drain. With these notions in mind, following our peregrinations through the Creek, we decided to select an underpass close to the city centre as the location for our filming to foreground its particularly striking qualities: the gloom through which the Creek flowed, the materialities of the concrete bridge and the bluestone setts underfoot, and the colourful graffiti that adorned the walls. Moreover, this setting would ensure that walking bodies dominated the frame but that the surrounding elements would also add to the affective and sensory charge of the film. In selecting this site, we engaged in solitary walking and note the ways in which this what? solicited a rich sensory and affective experience, undergirding for us the value of the Creek as a fertile space in which to walk. However, for the remainder of this section we focus on the values of collective walking, which the projection work foregrounds. In academic walking literature and creative practice, there remains a gap? in considering walking as a collective practice, with accounts of flaneurs, aloof or highly sensitised individuals continuing to predominate. Yet as Hayden Lorimer (2011, page) notes, reclaiming or reinscribing the right to place through collective walking has a long tradition in pilgrimages and rituals such as beating the bounds, as well as mass trespasses and protest marches.

Accordingly, we wished to foreground an exemplary episode that involved collectively walking the Creek to foster a sense of community and place that would extend beyond the event itself and pervade the effects and reception of the subsequent projection. The project was thus a co-production, drawing on a participatory approach guided by the objective to make place inclusive, by staging and recording the shared walking performance of diverse 
groups and individuals. Participants of different ages, ethnicities, and genders, of varying bodily capacities, sizes, and levels of fitness, and who were solitary or belonging to groups, congregated at the Creek and walked along the assigned route, passing through the aforementioned underpass where they were filmed (Figure 3). Some simply walked, others stopped to perform short dances, but all expressed different styles of moving, dispositions, clothing and gaits. Collectively, they configured the Creek as a public right of way by physically claiming this usually unfrequented realm as a site for walking, joining together in a convivial performance in which they shared embodied 'experiences of movement, rhythm, pace and direction' (Brown, 2012, p.811). In walking together, they expressed a distinctive form of sociability in movement, thereby revealing, as Maggie O’Neill (2008) describes, how group walking can build rapport among participants and work across communities of people who often regard themselves as having little in common.

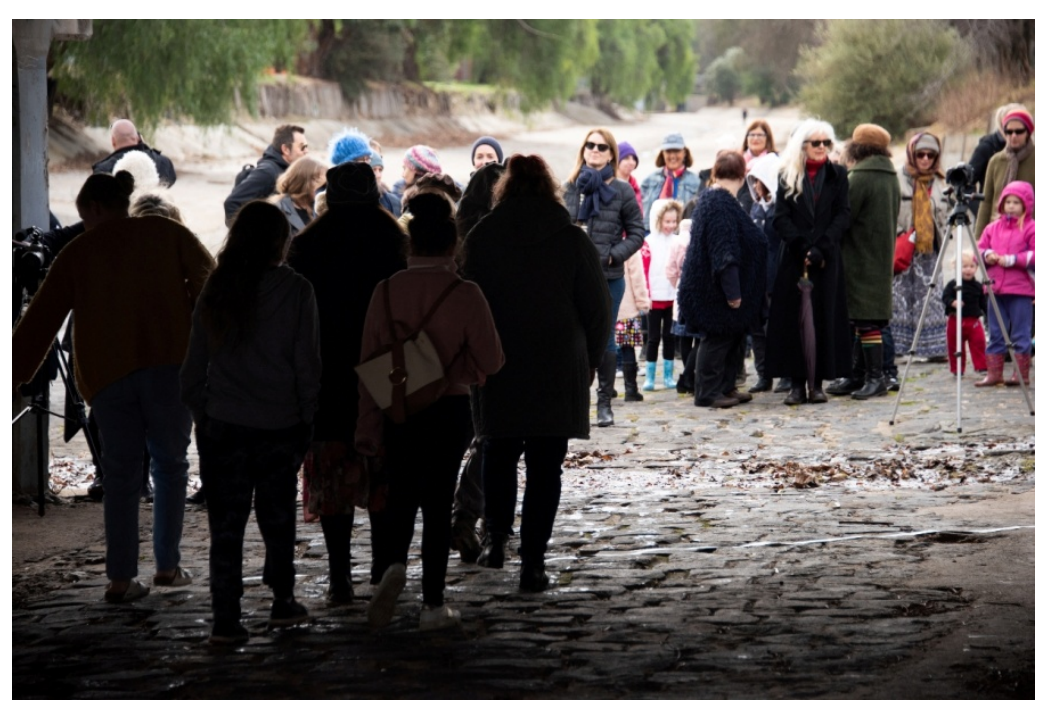

\section{Figure 3: walking participants assemble in the Creek}

Although walkers might be individually oriented to place and path, walking participants share a temporal and spatial co-presence as their bodies align with each other's pace and rhythm to create 'a common form that becomes familiar to both' (Vergunst, 2010, p.386). David Crouch (1998, p.167) extends this idea to focus on how this collective, mobile formation possesses the power to transmit a powerful collective statement of reterritorialization and shape the experience of onlookers: 
In their presence and in their movement, the bodies of self and of others, identified with similar purpose, feeling and direction, are dissolved into an intention and an identity that overwhelms any other image the street may hold; shops, houses, traffic, as these become culturally deafened by the ritual of occupation

Walking along the creek transmitted the sensory and affective charge generated by large numbers of moving bodies, as a "mob" (Shapiro, 2017), resonances that we aimed to accentuate through projection. The walking event was somewhat akin to the practice of flashmobbing, which takes several forms: it may be a brief disruptive action that subverts the usual use and meaning of commercial or private space; engage in expressive play or pranksterism to reclaim public space; be organized as part of a carefully choreographed advertising campaign; or, as here, be staged as part of an art event (Molnar, 2014). Although some commentators critique flash mobs for their presumed frivolousness and political pointlessness, others highlight how they can theatrically transform public space, undermining accepted practice and offering alternative visions of urban life. Beyond the Horizon sought both to convey an aesthetic impression and to broadcast the unrealised public potentialities that inhere in the disregarded urban realm of the Creek. In underlining its potential as a public space, we emphasise that walking together is a way of making place and community by encompassing difference in shared movement.

In the projection, some dancers also feature, performing underneath the bridge as walkers moved behind them. This informal site-specific dancing, solitary or in pairs, added an extra dimension to the event and to the projection, constituting a different way of reterritorializing place (Edensor \& Bowdler, 2015) and an especially expressive and affective means to imprint presence. The brief manoeuvres enacted here responded to the fixtures, micro-spaces, and surfaces of the site, locating a space between pillars to frame performance and, in one case, balancing between them horizontally.

This differently performed embodied engagement further draws attention to the distinctive affordances of the Creek in highlighting 'the particularities of the textures, forms and materials that combine and make up the urban landscapes in which we participate' (Hunter, 2017, p.30). Critically, such improvisatory expressions underline the ludic possibilities of 
urban spaces, transcending notions that roads, pavements, and rivers are merely functional sites of passage. They challenge the social conventions and the self-monitoring of movement that constrain bodies, side-stepping the normative rhythms that shape the habitual experience of place (Edensor, 2010), and evading surveillance. As Quentin Stevens (2007, p.40) asserts, the city provides myriad 'settings and props which can catalyse imaginative play'. Through dance, the Creek is reconfigured as a 'loose space' (Frank \& Stevens, 2007) in which activities are not prescribed and a playful 'prioritising of the non-cognitive and more-thanrational' may occur (Woodyer, 2012, p.319). Like industrial ruins (Edensor, 2008), walking in the Creek is often improvisatory and unsurveilled, disrupted by uneven terrain and distracted by surrounding sensory impressions. As we discuss below, the video seeks to further convey the pleasurable experience of using place otherwise, foregrounding the Creek's sensual and ludic potentialities, stimulating us to surmise how we might engage with the space. Like participants working with walking artist Misha Myers (2006, p.2), the walkers at the Creek mobilised a 'practical, embedded, embodied and responsive engagement' as part of a situated, knowledgeable, practical mode of inhabiting a part of their locale that could not be anticipated or programmed in advance of filming.

To emphasise, in devising the video projection for the Enlighten Festival, the objective was to capture and communicate the qualities of walking the Creek identified above - the affective and sensory qualities of the Creek, its liminal alterity, its capacity to inspire playfulness, the sense of communitas and the communicative potential generated by the crowd of walkers, the inclusionary incorporation of different bodies, and above all, the territorialization of a neglected urban space. We now turn to consider the projection in detail.

\section{Light art and projection}

Beyond the Horizon: The Lure of the Liminal Journey was displayed in Bendigo's Enlighten festival, a small, regional event solely focused on light projection, a still emerging creative practice. In the past 20 years or so, with the advent of mapping techniques and advanced technologies that have heightened luminosity, clarity, and scale, projections are currently an 
integral element of an expanding range and number of light festivals. These may be huge events such as Lyon's Fe $\square$ te des Lumières and Sydney's Vivid; smaller festivals such as those held at Durham, Singapore, and Eindhoven; and, like Enlighten, modest local occasions exclusively devoted to light projection. Light projections can draw attention to overlooked spaces, architectural features, iconic buildings, and monuments, and projection artists adopt many creative approaches: they may be abstract or realistic, static or animated, and play across surfaces of varying scale, texture, and function, upon façades, or onto small objects.

These light projection designs have the potential to render habitually apprehended environments suddenly strange, to produce what Fisher and Drobnick (2012, p.36) term 'the nocturnal carnivalesque', whereby familiar spaces are opened up to alternative interpretations and possibilities. In offering the chance to experience 'new modes of sense perception' (Rancière, 2009, p.9), creative projection can stimulate critical responses to the normative representation and experience of place.

This potentiality aligns closely with our intention to engender a reappraisal of the Creek through walking and representation. In reconfiguring the experience of space and place, projection can thus generate what Jane Bennett (2001, p.5) calls 're-enchantment' as we 'notice new colours, discern details previously ignored, hear extraordinary sounds, as familiar landscapes of sense sharpen and intensify'. Projected light can stimulate affective and sensory responses to rich colours, intense light, animated sequences and dramatic shadows (Edensor \& Bille, 2017), or through illusory manipulation, confounding perception by making buildings appear to dissolve, crumble, buckle, explode, or evaporate (Edensor, 2017). Yet though projection may alter habitual perceptions and assumptions, it also can heighten awareness of architectural form and texture, drawing attention to material constituents, adornments, and mundane? features. In addition, light projections and other illuminated installations may generate conviviality and promote a sense of inclusion. As crowds gather around these reconfigured nocturnal localities, atmospheres emerge that may be toned by a collective absorption in quiet contemplation or the hubbub generated by animated conversation (Edensor \& Sumartojo, 2018), further emphasising the broader potential of illumination to reanimate nocturnal space. 
In contrast, certain projection events are critiqued for their somewhat homogeneous design, as corporate sponsors fund renowned artists to project generic, far from place-specific works onto the facades of iconic local buildings. Undoubtedly, the proliferation of illuminationoriented events is entangled with neoliberal place-promotion strategies as "creativity" (Florida, 2005) is deployed to market cities to investors, tourists, shoppers and middle-class residents (Picard \& Robinson, 2006). Yet most projection festivals and installations tend to be site-specific (Giordano \& Ong, 2017), taking place in distinctive material and affective contexts, and in 'an actual location, a tangible reality, its identity composed of a unique combination of physical elements: length, depth, height, texture ... [and] distinctive topographical features' (Kwon, 2004, p.11). The Enlighten festival was thoroughly grounded in local community participation and artistic creativity was not compromised by commercial imperatives. It serves as an instance in which light can be deployed to re-enchant nocturnal space rather than produce over-illuminated, cluttered, corporate dominance or poorly illuminated realms, as other scholars have discussed (Entwistle et al., 2018; Isenstadt, 2018, Meier et al., 2014).

Beyond the Horizon was surrounded by other projections, creating a hub of conviviality and enticement, a saturated space of unfamiliar sounds and sights animated by the movement of visitors. Pools of affect accumulated and dispersed as people moved around and gathered to experience the different displays. Enlighten's projections featured various themes and styles: dancers from diverse cultural backgrounds gracefully moved along a balcony; an escalator ran across the pavement of a narrow ginnel; cartoon manga figures played in a shop window; animated flying saucers flew across a large disc situated in a tree. In addition, the arboreal landscape of the nearby Mount Alexander were projected onto a sliced and embroidered white sheet, brilliant and ever-changing colours swirled across the façade of the town hall, four local indigenous inhabitants painted their faces with traditional ochre designs across the facade of a nineteenth century conservatory. Elsewhere, an illuminated string of polaroid photographs hung in a shop window and down a dark alley, animated silhouetted figures articulated tributes to people and place. Each projection defamiliarized the space upon which 
it was projected while simultaneously bringing into focus the spatial, material and architectural qualities of these realms.

Beyond the Horizon, projected onto the window of Bendigo Library, was a centrally located installation within this panoply of light, and it attracted a steady stream of spectators each night. Small gaggles of onlookers congregated, commenting on dance moves and walking styles, and discussing the techniques and the aesthetics of the piece with their companions. Some gazed at the animated image for many minutes, while others briefly paused before moving on. Many scrutinized the projection to identify themselves, their friends or family members, shouting. or pointing gleefully once they had been spotted.

Enhanced by the projection was the recently built library, an inclusive and innovative community structure designed with expansive and flowing interior and exterior spaces to solicit multiple uses. Three large window sections, each divided into four vertical rectangular panes, were repurposed as large screens, echoing the tripartite structure of the video and suggesting how the library's functional and aesthetic qualities might be augmented. In addition to reconfiguring the experience of the building, the projection amplified the ludic, sensory, and affective qualities of the walk, and also intensified its liminal, inclusive, convivial, and place-making attributes. Most onlookers were aware that the Creek featured in the projection. While many walking participants brought along companions and spread the word about the work, both the walk and projection had plentiful coverage on local radio and in the Bendigo Advertiser newspaper (D'Agostino, 2018). Many locals recognised the distinctive thick bluestone setts of the Creek upon which walkers moved. Moreover, the festival programme and an in situ information board adjacent to the projection provided details of the walk's location and aims in supplementing other recent endeavours to reclaim the Creek as a local amenity.

A version of Beyond the Horizon before its projection onto the Library is located at this link: www.vimeo.com/292640606. The projection was created by remixing the recording of the original walking event, restaging it as a looped display of four-minute duration. In collaging particular elements, selectively featuring certain walkers and dancers, and reordering the sequence in which they appeared, the work composed a shorter yet inclusive impression of 
the participants. In reconfiguring the walk, the moving image was significantly altered. The background was significantly darkened so that only basic textural and structural characteristics - the bluestone setts and concrete pillars and walls-remained visible. The human figures, on the other hand, were converted into silhouettes through which the background became highly visible, accentuating the texture of the concrete and the vibrant graffiti daubed on the walls of the underpass. The inclusion of two pillars created a triptych, with the central section more brightly illuminated than the softer, sepia-toned sections that flanked it. These side sections featured a steady stream of pedestrians, while the central section intermittently included the more dynamic movements of dancers. In downplaying certain features and highlighting others, the projection sought to convey some of the material, sensory and affective qualities of the Creek. While enhancing the site's strangeness and unfamiliarity, the work also sought to inspire onlookers to connect with its historical and contemporary salience.

Critically, in intensifying a visceral sense of being and walking in the Creek, the remixed projection aimed to foreground the walking and dancing participants to emphasise that the work was a co-production. The convivial atmosphere of the occasion can be gauged by the animated ways of walking and the obvious enjoyment expressed by the dancers who bestowed their own presence and improvisational styles on the projection. The inclusivity of the procession was evident in the diversity of ages and ethnicities of pedestrians, with bodies of all shapes and sizes marking their presence as part of the Bendigo community. In their walking performance, these participants-white, Aboriginal, Torres Strait Islander, refugee, migrant and artist—exemplified how the Creek might be returned to the public realm. In addition, the swirls of graffiti ensured that absent co-producers were also honoured, revealing that some local people have already made creative use of the spaces of the Creek.

As the subtitle, The Lure of the Liminal Journey, indicates, the projection sought to bring out the quality of the Creek as a distinctive kind of liminal space that solicited a particular walking experience. It also endeavoured to produce a work that evoked a sense of liminality in itself. Liminal space has been ascribed as both psychically and physically positioned outside of habitually experienced realms. Such marginal or transitional spaces offer 
alternative possibilities because they are places into which few people venture; they are loosely regulated and therefore not saturated with conventions that constrain action and interpretation. Despite running through the centre of Bendigo, the Creek certainly fits the description of marginal, remaining a largely unoccupied channel ignored by planners, placepromoters and pedestrians. Moreover, as we have elaborated, walking through the Creek is charged with a sensory alterity as the muffled noises of the city resound within its depths, with softly trickling water, the vital sky above, and the flutters and rustles of non-humans. The Creek's unique material constitution and spatial configuration further underpin an impression of its physical liminality, with its deep u-shaped channel, bluestone setts, and occasional bridges and tunnels. Andrews and Roberts (2012, p.1) also claim that liminal qualities can also be expressed as a 'duration in the unfolding of a spatio-temporal process', in which new forms, practices or relationships emerge. In this regard, walking through the Creek evokes van Gennep's original description of liminality as shaped by the successive rites of separation, transition, and incorporation (Thomassen, 2009, p.6): walkers entered an unfamiliar, discrete realm in which they underwent a very different sensory and affective experience, a temporary diversion from the habitual apprehension of the usual byways of the city.

In the subsequent remixing of the event as a projection, a key aim was to capture this strange experience of walking in the Creek, while also charging it with qualities that might intensify an impression of these embodied and affective resonances. In the projection, the physical and psychic liminality of the space of the Creek as it passes under the bridge are conveyed, with its gloom, monochrome concrete pillars, bluestone setts, and colourful background graffiti. These peculiarities are intensified by the slowed down, dream-like procession of pedestrians as they move behind and between the rectilinear pillars, augmented by the intermittent appearance of dancers in the foreground. In suggesting that time seemed to slow down, the work sought to deepen the impression that the Creek is a realm of alterity, a twilight zone inhabited by unpredictable ghostly forms, perhaps the spectres of previous bodies that may have inhabited this venerable space, people who passed briefly through or worked on building and maintenance. Besides undergirding its historical depth, this impression of 
temporal alterity and the subtle interplay of colour and shadow were intended to work at a sensory and affective level, soliciting a compelling, mysterious impression of the space of the Creek.

Yet, although the projection conveyed a sense of liminal time and space, by situating the work at eye level and projecting pedestrians at normal size, it also aimed to engender physical empathy. Like other screen images of active human bodies within a landscape, footage of walking solicits a tactile gaze. As Vivian Sobchack (2004) declares, the consumption of moving images of human bodies solicits a multi-sensual experience; we surmise that observing the pedestrians in Beyond the Horizon will stimulate vicarious sensations of touch, proprioception, shadow, light, and textures underfoot. And since walking is an everyday practice, ubiquitously engaged in by citizens past and present, walking the Creek chimes with what is already a quotidian practice for most spectators. By reterritorializing this neglected space, the projection demonstrated that it is a realisable venue for walking and reconfigures the Creek as replete with possibilities. Rather than a space of presumed inaccessibility, it can become a site of mobility, a ludic, sensory, and expressive place that may host a range of unprescribed activities. The remix of the event thus contributes to the honouring of this site, confirming Alves's (2007, p.1259) assertion that light installations can foment 'a sense of belonging to and understanding of places, giving new meanings so that territories are repossessed'. In aiming to communicate a poetic, sensory, and affective sense of the Creek's liminality by foregrounding its distinctive affordances, the projection endeavoured to encourage new ways of seeing, thinking about and experiencing this largely ignored element of Bendigo's built environment.

\section{The mobile projector}

As we have explained, Beyond the Horizon relied on cutting-edge film making and production, underlining how light festivals are events that bring together arts administrators and managers, cultural entrepreneurs, artists, engineers, technicians, and designers. As Nona Schulte-Ro $\square$ mer (2013, p. 152) articulates, these events serve as occasions at which temporary collaborations and new networks of association 'offer different social groups open access and a variety of opportunities to share experiences and encounter the new'. Without 
this sharing of techniques and aesthetic possibilities, it would have been impossible to create the projection. The manipulation of the film was deployed via a programme called the difference blending mode through which the colours of pixels were remixed to produce the range of colour and brightness integral to the aesthetic qualities of the finished piece.

Fostering technological and artistic possibilities also extended to the nightly use of a mobile projector which enabled us to roam through the streets, parks, and alleyways of central Bendigo and project the footage on any surface we desired. While a bicycle with a large appliance attached to the back and a projector affixed to the handlebars to transmit images was available, we deployed a more flexible device, a portable backpack containing a smaller appliance connected to a hand-held projector.

The mobile projector affords opportunities to briefly colonise parts of the city unreachable by static projectors, expanding the scope for reanimating the city after dark, playing with its built forms and fixtures. This method? has the potential to reattune us to the city's textures and forms. Walking together or in larger groups, we projected the walkers in the Creek onto an array of surfaces, including an old cobbled lane, the rough bark of a tree, refuse bins, electricity containers, cars, through the slats of a bench, and pedestrian's bodies (Figure 4). In addition, we complemented some of Enlighten's other works, providing points of contrast and counterpoint by "projection bombing" them, and also invaded forms of street art, signs, and notices to reconfigure their design, filling in blank spaces, and augmenting their colours. Moving through the city, wantonly shining the image of the pedestrians on an assortment of available surfaces, we further populated the city with their animated movements. This defamiliarized fixtures and facades, and further construed the city as a ludic space (Stevens, 2007), underlining the notion that it should be as accessible as possible to its inhabitants. Groups or individuals followed our playful journeys around the city or were diverted by the surprising appearance of projection upon an everyday fixture, helping to catalyse the effects of illuminated images at night and fostering convivial interaction. Like the guerrilla illuminations deployed to inscribe temporary political messages and images across the nocturnal city (Edensor, 2015), this is a form of temporary graffiti, one which does not 
endure for as long as painted inscriptions but nonetheless, supplements and challenges the all too often commercial textual and representational elements of the city.
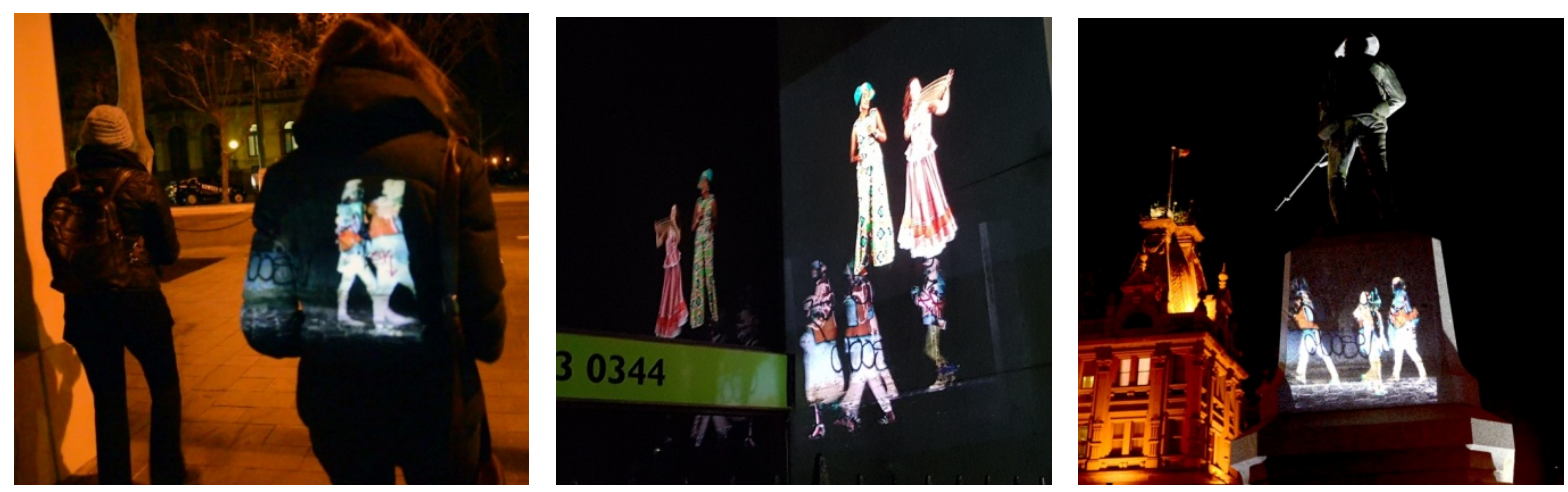

\section{Figure 4: Mobile projections}

The use of the mobile projector also attuned us to the levels of light that play across the city. By night, illumination animates shapes and surfaces often overlooked in daylight. And sites not apparently gloomy are revealed to be actually quite dark since the projection shone clearly, whereas sites saturated with an abundance of ambient light caused the projected image to appear pallid and indistinct. Moreover, the colours of surfaces affected the luminosity of the image, with plain dark colours, white, and orange particularly conducive to bright, clear images. The diverse tones, colours, and intensities of central Bendigo's quotidian lightscape was brought to attention. In continuously assessing the luminosity and tone of the surroundings through light projection, we could identify where "light clutter" drenched the urban night. This what? revealed how projections shine in illuminated concord or dissonance with the everyday 'light world' of Bendigo's nocturnal streets (Pink and Sumartojo, 2017), and demonstrated how light could configure urban realms in multiple different ways in festive and everyday applications.

\section{Conclusion}

In this paper, we have demonstrated how a light projection, Beyond the Horizon: The Lure of the Liminal Journey, staged at Bendigo's Enlighten festival, aimed to convey the conviviality, sense of place, material qualities, and the affects and sensations that might be experienced through walking in the city's distinctive Creek. In deploying advanced post- 
production techniques and remixing the footage to accentuate certain levels of light, colour, and texture, by dividing up the footage and superimposing scenes, and by altering the speed of the walkers, we have exemplified how the liminal alterity of the Creek was intensified in the projection. The projection aspired to solicit a sensory and affective empathy from onlookers so that they might vicariously experience the feeling of the event and the space, and reassess the qualities of their much-maligned Creek.

We have sought to show how the walk along the Creek and its subsequent projection were expressions of reterritorialization devised to support campaigns to bring it back into everyday space as a public amenity. In so doing, we suggest that publicly engaged creative practice can contribute to progressive place-making by reconnecting with histories, celebrating overlooked affordances and suggesting the multiple performative potentialities of neglected public spaces.

In featuring the event of the walk, the static projection on Bendigo's library, and the images cast by the mobile projector, we have both promoted the ludic potential of the city, and emphasised the capacity of publicly sited projections to inclusively draw in those who may not regularly consume art in more formal settings. This what? was affectively amplified by the convivial ambiance of the walk, the potent atmospheres that accumulated and dispersed around the library, and the clusters of spectators who followed the operators of the mobile projector to witness how it might alter the usual apprehension of familiar space.

The remixing and restaging of the walk via projection is somewhat akin to the situationist practice of détournement (Debord \& Wolman, 2007) whereby different images or texts are recombined to form something new. This remixing refocused on selective qualities of conviviality, sensation, materiality, and liminality, while mobile projection temporarily transformed a wealth of objects, structures, and surfaces into temporary screens. We contend that remixing might be considered to be a potent way of reconfiguring place by amplifying particular affordances to effect a "thickening of space" and soliciting an experience through which such realms might be honoured, re-imagined, vicariously sensed, and affectively communicated (Holloway, 2017). Projection and remixing thus offers critical opportunities to 
transmit alternative identities, political ideas and cultural values about place (Picard \& Robinson 2006).

\section{References}

Andrews, H. and Roberts, L. 2012. Introduction: re-mapping liminality, in H. Andrews and L. Roberts, eds, Liminal Landscapes: Travel, Experience and Spaces In-between, London: Routledge.

Alves, T. 2007. Art, light and landscape: New agendas for urban development. European Planning Studies 15(9):1247-1260. doi:10.1080/09654310701529243.

Bassett, K., 2004. Walking as an aesthetic practice and a critical tool: Some psychogeographic experiments. Journal of Geography in Higher Education, 28(3): 397-410. (accessed 10/8/18)

Bennett, J. 2001. The enchantment of modern life: Attachments, crossings and ethics. Princeton, NJ: Princeton University Press.

Brown, K. 2012. Sharing public space across difference: attunement and the contested burdens of choreographing encounter, Social and Cultural Geography, 13(7): 801-820 Courage, C. and McKeown, A. eds., 2018. Creative Placemaking: Research, Theory and Practice. London: Routledge.

Crouch, D. 1998. The street in the making of popular geographical knowledge', in N. Fyfe, ed. Images of the Street: Planning, Identity and Control in Public Space, ed. London, Routledge, pp. 160-175.

D’Agostino, B. (9/7/18) 'Bendigo Creek to shine during Enlighten Festival', https://www.bendigoadvertiser.com.au/story/5515460/bendigo-creek-to-shine-duringenlighten-festival/?cs $=80$

Debord, G. and Wolman, G. 2007. A user's guide to détournement, in K. Knabb, ed. 
Edensor, T. 2008, Walking through ruins, in J. Vergunst and T. Ingold, eds. Ways of Walking: Ethnography and Practice on Foot, London: Routledge, 135-154

Edensor, T. 2010, Walking in rhythms: place, regulation, style and the flow of experience, Visual Studies, 25(1): 69-79

Edensor, T., 2015. The gloomy city: Rethinking the relationship between light and dark. Urban Studies, 52(3): 422-438.

Edensor, T. 2017. From Light to Dark: Daylight, Illumination and Gloom. Minneapolis: Minnesota University Press.

Edensor, T..2018. Moonraking: Making things, place and event., in L. Price and H. Hawkins, eds. Geographies of Making/making Geographies: Embodiment, Matter and Practice, London and New York: Routledge, pp. 60-75.

Edensor, T. and Bowdler, C. 2015, Site-specific dance: revealing and contesting the ludic qualities, everyday rhythms, and embodied habits of place, Environment and Planning A 47: 709-726

Edensor, T. and Sumartojo, S. 2018. Reconfiguring familiar worlds with light projection: The Gertrude Street Projection Festival, 2017. GeoHumanities, 4(1): 112-131.

Entwistle, J., Bordonaro, E. and Slater, D., 2018. The social study of urban lighting. In:

Davoudian, N. ed. Urban Lighting for People. RIBA Publishing, London,

Fisher, J., and J. Drobnick. 2012. Nightsense. Public 23(45):35-63.

doi:10.1386/public.23.45.35_1.

Florida, R. 2005. Cities and the Creative Class. London: Routledge.

Frank, K. And Stevens, Q. 2007. Tying down loose space, in K. Frank and Q. Stevens, eds. Loose Space: Possibility and Diversity in Urban Life. Abingdon, UK: Routledge.

Gabrys, J. 2012. Becoming urban: sitework from a moss-eye view, Environment and Planning A, 44: 2922 - 2939 
Giordano, E. and Ong, C.E. 2017. Light festivals, policy mobilities and urban tourism. Tourism Geographies, 19(5): 699-716.

Holloway, J. 2017. Resounding the landscape: the sonic impress of and the story of Eyam, plague village, Landscape Research, 42(6): 601-615,

Hunter, V. 2017. Perecquian perspectives: dialogues with site-dance (or, 'on being here and there') Literary Geographies 3(1): 27-49

Ingold, T. 2000. The Perception of the Environment: Essays on Livelihood, Dwelling and Skill, London: Routledge.

Isenstadt, S. 2018. Electric Light: An Architectural History. Cambridge, MA: MIT Press Kay, G. and Moxham, N. 1996. Paths for whom? countryside access for recreational walking, Leisure Studies 15: 171-83.

Kernebone, E. (20/7/18). 'LaTrobe's City Studio project comes to Bendigo', Bendigo Advertiser, https://www.bendigoadvertiser.com.au/story/5534997/citystudio-helps-studentsbring-creative-solutions-to-bendigo-creek/?cs $=80$

Kwon, M. 2004. One Place after Another: Site-specific Art and Locational Identity. Cambridge, MA: MIT Press.

Lawrence, S., Davies, P. and Turnbull, J. 2017. The archaeology of water on the Victorian goldfields. International Journal of Historical Archaeology, 21(1), pp.49-65.

Lorimer, H. 2016. Walking: new forms and spaces for studies of pedestrianism, in T. Cresswell and P. Merriman, eds. Geographies of Mobilities: Practices, Spaces, Subjects, London: Routledge. pp. 31-46

Lund, K. 2012. Landscapes and narratives: compositions and the walking body', Landscape Research, 37(2): 225-237,

Meier, J., Hasenöhrl, U., Krause, K. and Pottharst, M. eds. 2014. Urban Lighting, Light Pollution and Society. London: Routledge. 
Molnár, V. 2014. Reframing public space through digital mobilization: Flash mobs and contemporary urban youth culture. Space and Culture, 17(1), pp.43-58.

Myers, M. 2006 Along the way: situation-responsive participation and education, International Journal of the Arts in Society, 1(2): 1-6

Picard, D., and M. Robinson. 2006. Remaking worlds: Festivals, tourism and change, in D. Picard and M. Robinson, eds. Festivals, Tourism and Social Change: Remaking Worlds, Clevedon, UK: Channel View. pp. 1-31.

Pinder, D. 2011 Errant paths: the poetics and politics of walking, Environment and Planning D: Society and Space, 29: 672-692

Pink, S., Hubbard, P., O'Neill, M. and Radley, A. 2010. Walking across disciplines: from ethnography to arts practice, Visual Studies, 25(1): 1-7

Pink, S., and S. Sumartojo. 2017. The lit world: Living with everyday urban automation. Social and Cultural Geography doi:10.1080/14649365.2017.1312698.

Rybra $\square$ ten, S., Ska $\square$ r, M. and Nordh, H. 2017. The phenomenon of walking: diverse and dynamic, Landscape Research, DOI: 10.1080/01426397.2017.1400527

Sobchack, V. 2004. Carnal Thoughts: Embodiment and Moving Image Culture. Berkeley: University of California Press.

Schulte-Ro $\square$ mer, N. 2013. Fair framings: Arts and culture festivals as sites for technical innovation. Mind and Society 12(1):151-65..

Shapiro, A. 2017. The medium is the mob. Media, Culture \& Society, 39(6), pp.930-941.

Stevens, Q. 2007. The Ludic City: Exploring the Potential of Public Spaces London:

Routledge,

Thomassen, B. 2009. The uses and meanings of liminality. International Political Anthropology, 2(1), pp.5-27.

Vergunst, J. 2010. Rhythms of walking: history and presence in a city street, Space and Culture 13(4): $376-388$

This article is protected by copyright. All rights reserved. 
Waitt, G., Gill, N. and Head, L. 2009. Walking practice and suburban nature-talk, Social and Cultural Geography,10(1): 41-60

Waterton, E., 2018. Curating affect: exploring the historical geography-heritage studies nexus at Sovereign Hill. Australian Geographer, 49(1): 219-235.

Woodyer, T. 2012. Ludic geographies: not merely child's play, Geography Compass 6: 31332

Wylie, J. 2005. A single day's walking: narrating self and landscape on the South West Coast Path, Transactions of the Institute of British Geographers 30(2): 234-247 


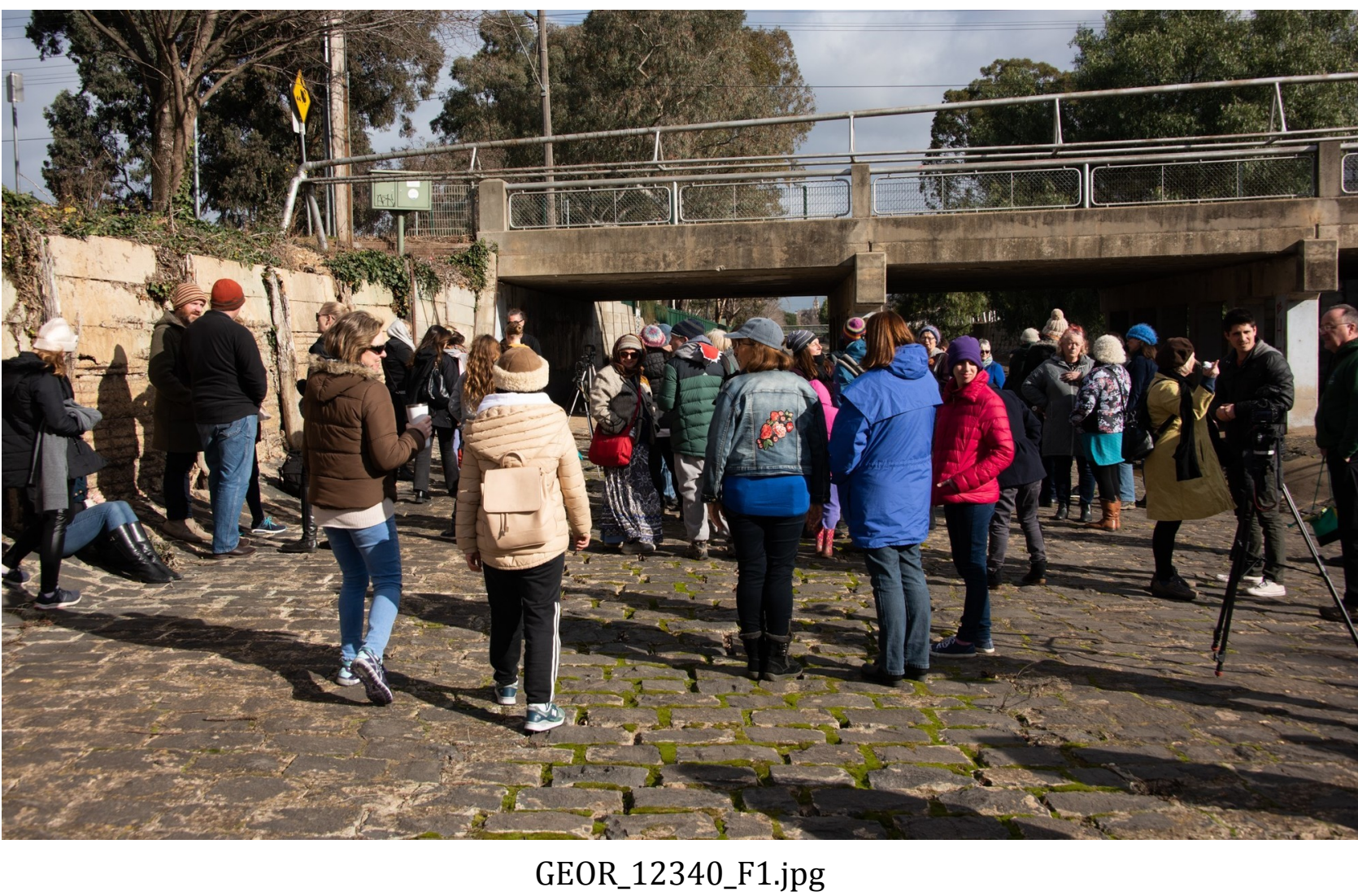

This article is protected by copyright. All rights reserved. 


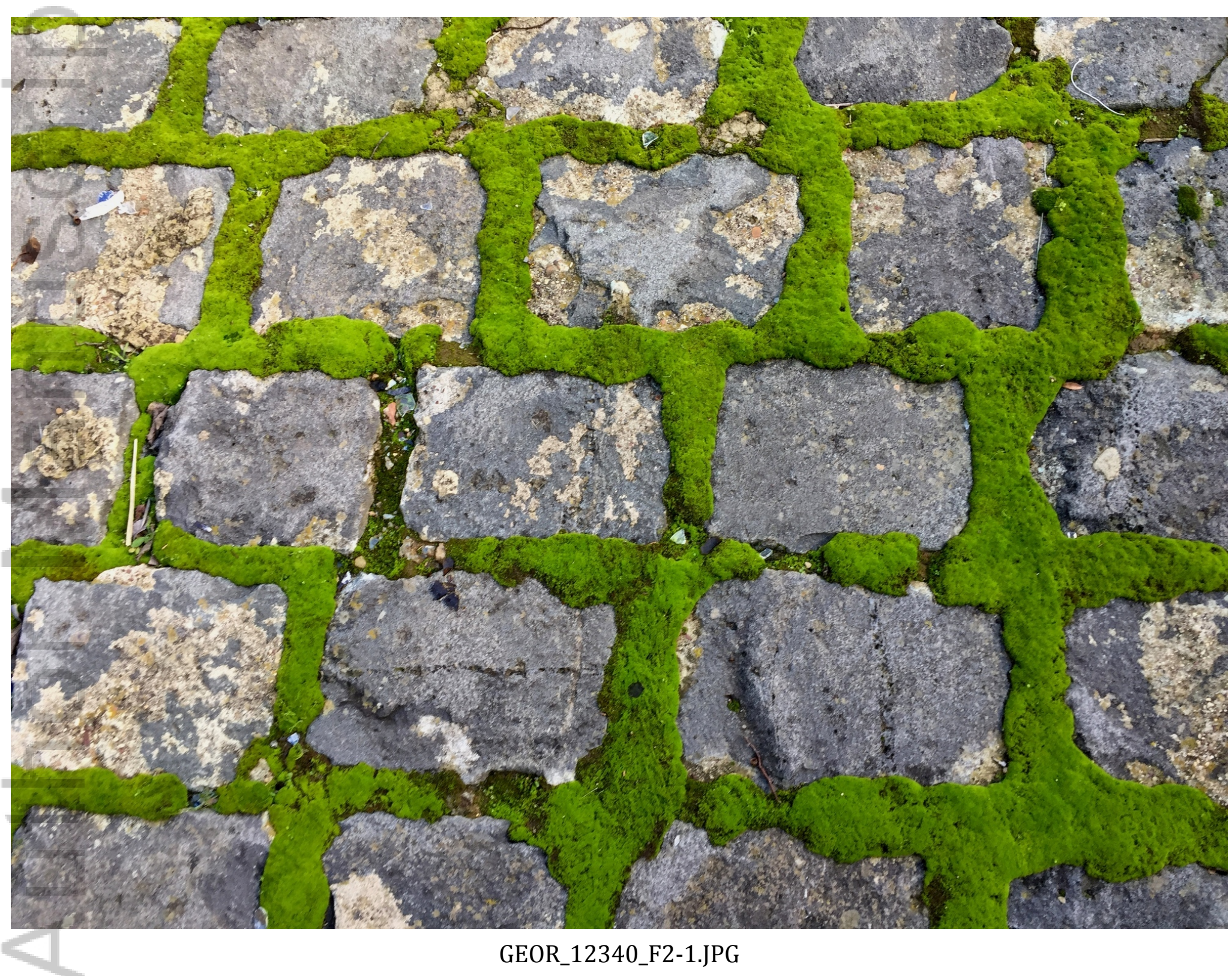

This article is protected by copyright. All rights reserved. 


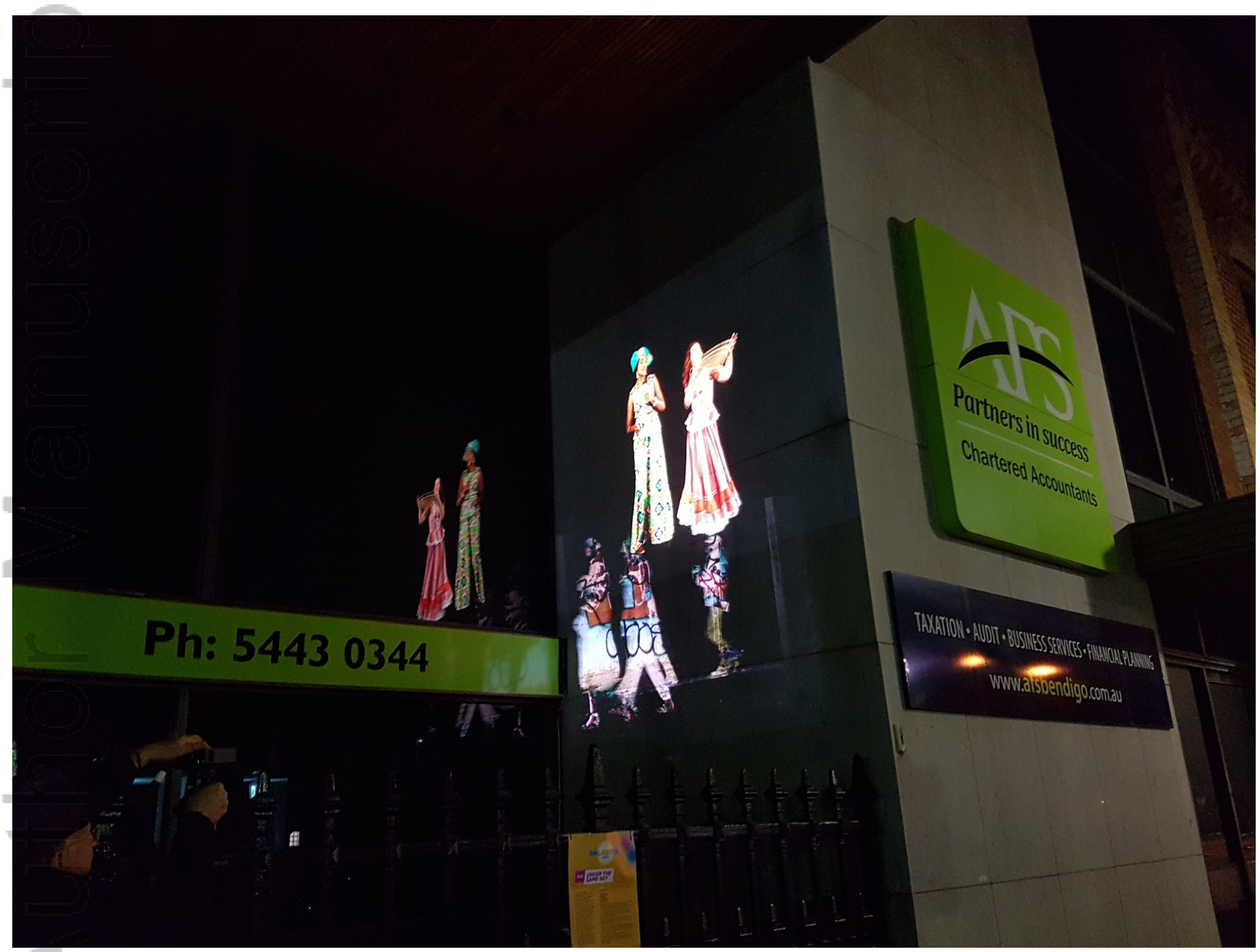

GEOR_12340_F4-1.jpg

This article is protected by copyright. All rights reserved. 
